\title{
Carbohydrate 19.9 Antigen Serum Levels in Liver Disease
}

\author{
Gaetano Bertino, ${ }^{1}$ Annalisa Maria Ardiri, ${ }^{1}$ Giuseppe Stefano Calvagno, ${ }^{1}$ \\ Giulia Malaguarnera, ${ }^{2}$ Donatella Interlandi, ${ }^{1}$ Marco Vacante, ${ }^{3}$ Nicoletta Bertino, \\ Francesco Lucca, ${ }^{3}$ Roberto Madeddu, ${ }^{4}$ and Massimo Motta ${ }^{3}$ \\ ${ }^{1}$ Department of Medical and Pediatric Sciences, Hepatology Unit, University of Catania, 95123 Catania, Italy \\ ${ }^{2}$ International Ph.D. Program in Neuropharmacology, University of Catania, 95123 Catania, Italy \\ ${ }^{3}$ Research Center "The Great Senescence", University of Catania, 95125 Catania, Italy \\ ${ }^{4}$ Department of Biomedical Sciences, University of Sassari, 07100 Sassari, Italy
}

Correspondence should be addressed to Giulia Malaguarnera; giulia.malaguarnera@live.it

Received 23 June 2013; Revised 10 September 2013; Accepted 12 September 2013

Academic Editor: Aleksandra Nikolic

Copyright (c) 2013 Gaetano Bertino et al. This is an open access article distributed under the Creative Commons Attribution License, which permits unrestricted use, distribution, and reproduction in any medium, provided the original work is properly cited.

Background. Carbohydrate 19.9 antigen (CA19.9) has been used in the diagnosis and followup of gastrointestinal tumours. The aim of this prospective longitudinal study was the evaluation of CA19.9 levels in patients with chronic hepatitis and hepatic cirrhosis hepatitis C virus and B virus correlated. Materials and Methods. 180 patients were enrolled, 116 with HCV-related chronic liver disease (48\% chronic hepatitis, 52\% cirrhosis) and 64 with HBV-related chronic liver disease (86\% chronic hepatitis, $14 \%$ cirrhosis). Patients with high levels of CA19.9 underwent abdominal ecography, gastroendoscopy, colonoscopy, and abdominal CT scan. Results. $51.7 \%$ of patients with HCV-related chronic liver disease and $48.4 \%$ of those with HBV-related chronic liver disease presented high levels of CA19.9. None was affected by pancreatic or intestinal neoplasia, cholestatic jaundice, or other diseases potentially able to induce Ca19.9 elevations. CA19.9 levels were elevated in 43.3\% of HCV chronic hepatitis, in 56.3\% of HCV cirrhosis, in $45.1 \%$ of HBV chronic hepatitis, and in 58\% of HBV cirrhosis. Conclusions. CA19.9 commonly increases in the serum of patients with chronic viral hepatitis. Elevation of CA 19.9 is not specific for neoplastic disease and is related to the severity of fibrosis and to the viral aetiology of hepatitis.

\section{Introduction}

CA19.9 is a glycoprotein expressed by several epithelial cancers, as well as in normal pancreatic and biliary duct epithelia, and it is used currently in the diagnosis and followup of gastrointestinal tumours $[1,2]$. High levels of CA19.9 have been observed in patients with gastric adenocarcinoma, in colon, biliary duct, and pancreatic carcinomas [3-6]. Patients affected by chronic diseases such as pancreatitis, renal failure, and chronic liver disease showed a significant reduction of CA19.9 specificity [7]. The CA19.9 immuno-reactivity was observed in bile ductules and interlobular bileducts of nonneoplastic areas surrounding hepatocellular carcinoma [8].

CA19.9 levels increase in non-neoplastic and organspecific diseases such as acute and chronic pancreatitis, cholelithiasis, cholecystitis, achalasia, acute hepatitis, hepatic cirrhosis, and respiratory diseases and in systemic diseases such as diabetes mellitus and rheumatic and autoimmune disorders. CA19.9 serum levels can be used as marker for the followup of chronic organ-specific inflammations, such as prostatitis [9-16]. An increase in CA19.9 serum levels has been reported in nonneoplastic liver disease such as simple liver cysts, severe steatosis, autoimmune hepatitis, chronic alcoholic hepatitis, and hepatic cirrhosis [16, 17], where CA19.9 levels seem to correlate with the grade of fibrosis and cholestasis [17].

The aim of this study was to evaluate serum CA19.9 levels in a cohort of subjects affected by chronic HCVcorrelated (CHC) and HBV-correlated hepatitis (CHB), in order to evaluate whether elevated CA19.9 serum levels can be considered a non casual event and/or could depend on the viral infection ( $\mathrm{HCV}$ or $\mathrm{HBV})$. We also investigated 
the correlation between CA19.9 serum levels and the severity of the liver disease.

\section{Methods and Materials}

2.1. Patients. Eligible patients for this prospective longitudinal study were those who were 18 years of age or older, were infected by HCV genotype $1 \mathrm{~b}$ (as determined with the use of the INNO-LiPA assay), and had a quantifiable $(>6.90 E+07 \mathrm{IU} / \mathrm{mL}$ ) serum HCV RNA level (as determined by polymerase chain reaction, COBAS AmpliPrep/COBAS TaqMan-ROCHE) and those who were infected by HBV, with positivity to HBsAg (as determined with CLIA technique) and quantifiable HBV DNA serum level (as determined with the use of PCR-based analysis). Both HCV- or HBV-infected populations must had elevated serum alanine transaminase levels and findings on liver biopsy consistent with chronic infection. Cirrhotic patients had to have a Child-Pugh score less than 7 to be eligible. Ineligible patients were those who had other liver diseases, as well as those who were affected by cancer, severe jaundice, pulmonary and renal chronic diseases, prostatic diseases, autoimmune diseases, and diabetes mellitus. None of the patients made excessive use of alcohol ( $>20 \mathrm{~g} / \mathrm{die})$ or hepatotoxic drugs. Study recruitment was performed in observation and respect of Helsinki Declaration. All patients gave their informed consent for the study participation and for each invasive procedure they underwent. All sensitive data were collected and protected in respect of present privacy statements. From November 2007 to January 2009, 180 eligible patients have been enrolled (108 males, 72 females). The entire cohort is split into two groups depending on the viral aetiology: Group 1 contains HCV-infected subjects ( 74 males, 42 females; mean age 54 , range $35-73$ years); Group 2 contains HBV-infected subjects (34 males, 30 females; mean age 53, range 3475 years). Clinical evaluations, hematochemical, virological, instrumental, and histological analysis were performed on these patients.

2.2. Laboratory Analysis. The following serum analyses are reported in details: renal function tests, serum $\mathrm{K}^{+}$and $\mathrm{Na}^{+}$, fasting and postprandial glucose, PSA (prostatic specific antigen) serum assay, AST and ALT (aspartate aminotransferase and alanine aminotransferase), $\gamma \mathrm{GT}$ (gamma glutamil tranferase), alkaline phosphatase, total, conjugated and unconjugated bilirubin, cholinesterase, serum proteins, prothrombin, fibrinogen, and prothrombin time (PT) analysis were performed. Chemical and physical urine exam was also performed. All patients underwent a complete virological assay for HBV and HCV. HBsAg (hepatitis B surface antigen), anti-HBc IgG (hepatitis B "core" IgG antibody), HBeAg (Hepatitis B "e" antigen), HBeAb (hepatitis B "e" antibody), HBV-DNA (hepatitis B virus DNA), anti-Delta (Delta virus antibody) assays were performed. Genomic analysis for HBV-DNA and HBV genotypes was performed using COBAS AmpliPrep and INNOLIPA Genotyping assay. Anti$\mathrm{HCV}$ antibodies were determined by ELISA (Enzyme-Linked immunosorbent assay ELISA assay-Ortho Diagnostic Systems, Raritan, NJ, USA). HCV-RNA (Hepatitis C Virus RNA) levels were detected by polymerase chain reaction (PCR) of HCV-RNA 5'UTR using COBAS AmpliPrep/COBAS TaqMan (Roche Diagnostics Systems, Branchburg, N.J). HCV viral genotypes were determined by restriction analysis of HCV-RNA $5^{\prime}$ UTR, using Simmonds' classification [18]. Anti-nuclear (ANA), anti-mitochondrial (AMA), antismooth muscle (SMA), anti-liver/kidney microsome type 1 (LKM1) auto-antibodies were measured using immunofluorescence assay (IFA) and semi-quantitative ELISA immobilizing enzyme test. Thyroid function was evaluated by levels of TSH (Thyroid-Stimulating Hormone) (WHO 2nd IPR 80/558-ECL), free T3 (free-Triiodothyronine) and free T4 (free-Tetraiodothyronine T4) that were determined by immunoradiometric assay (IRMA) and antibodies against thyroid peroxidase and thyroglobulin were measured by IFA. Serum C3 and C4 assay was performed. Serum levels of iron (n.v. $55-160 \mathrm{mg} / \mathrm{dL}$ in men, $45-150 \mathrm{mg} / \mathrm{dL}$ in women), saturated transferring (n.v. 2-36 g/L), total transferrin (total iron binding capacity, TIBC n.v. $218-411 \mathrm{mg} / \mathrm{dL}$ ), unsatured transferrin (unsatured iron binding capacity, UIBC n.v. 110$290 \mathrm{mg} / \mathrm{dL}$ ) and ferritin (n.v. 18-370 ng/mL) were determined, and saturation of transferrin was calculated as: serum level of iron/TIBC $\times 100$ v.n. $0-40$. Genetic testing to identify hemochromatosis HFE gene mutations was performed in order to exclude subjects with hereditary hemochromatosis. CA19.9 measurement was performed in all patients by ECL method Elexis COBAS (n.v. 0.0-39.0 UI/mL) using a commercial kit (CA19.9 diagnostic immunoassay-ROCHE) based on company's instructions. The standard cut-off value $(100 \mathrm{UI} / \mathrm{mL})$ grants a sensitivity and specificity of $96 \%$ and $90 \%$, respectively. All liver function tests, hematochemical and hormonal measurements, and virological analysis have been executed in the laboratory of our hospital with automated and standardized methods, in conformity to the quality certified standards EN ISO 9001:2000.

2.3. Histological Assessment of the Liver. Patients underwent ultrasound-assisted percutaneous biopsy: tissue specimens were obtained with Menghini modified needles (automatic aspiration needle for liver biopsy, ACR 16G, $11 \mathrm{~cm}$, manufactured by Sterylab Srl, Milan; Italy). A Specimen $5 \mathrm{~cm}$ long and containing at least 6 portal spaces was considered significant. Histological evaluation of the grade of necroinflammatory activity (grading) and fibrosis (staging) of hepatic tissue was carried out using the METAVIR scoring system [19].

Patients who resulted positive to high serum levels of CA19.9 were subjected to perform abdominal and thyroid ecography, thorax radiography, Esophagogastroduodenoscopy (EGD), colonoscopy, and thorax and abdominal spiral TC. Clinical, instrumental, and laboratory investigations allowed to exclude other causes of serum CA19.9 elevation: pancreatic, intestinal, ovarian, mammalian, and prostate tumours, chronic respiratory disease, autoimmune diseases, rheumatic disease, inflammatory bowel diseases, cholestatic jaundice, and hereditary hemochromatosis. Baseline characteristics of the study cohort are shown in Table 1. 
TABLE 1: Baseline characteristics of the study cohort.

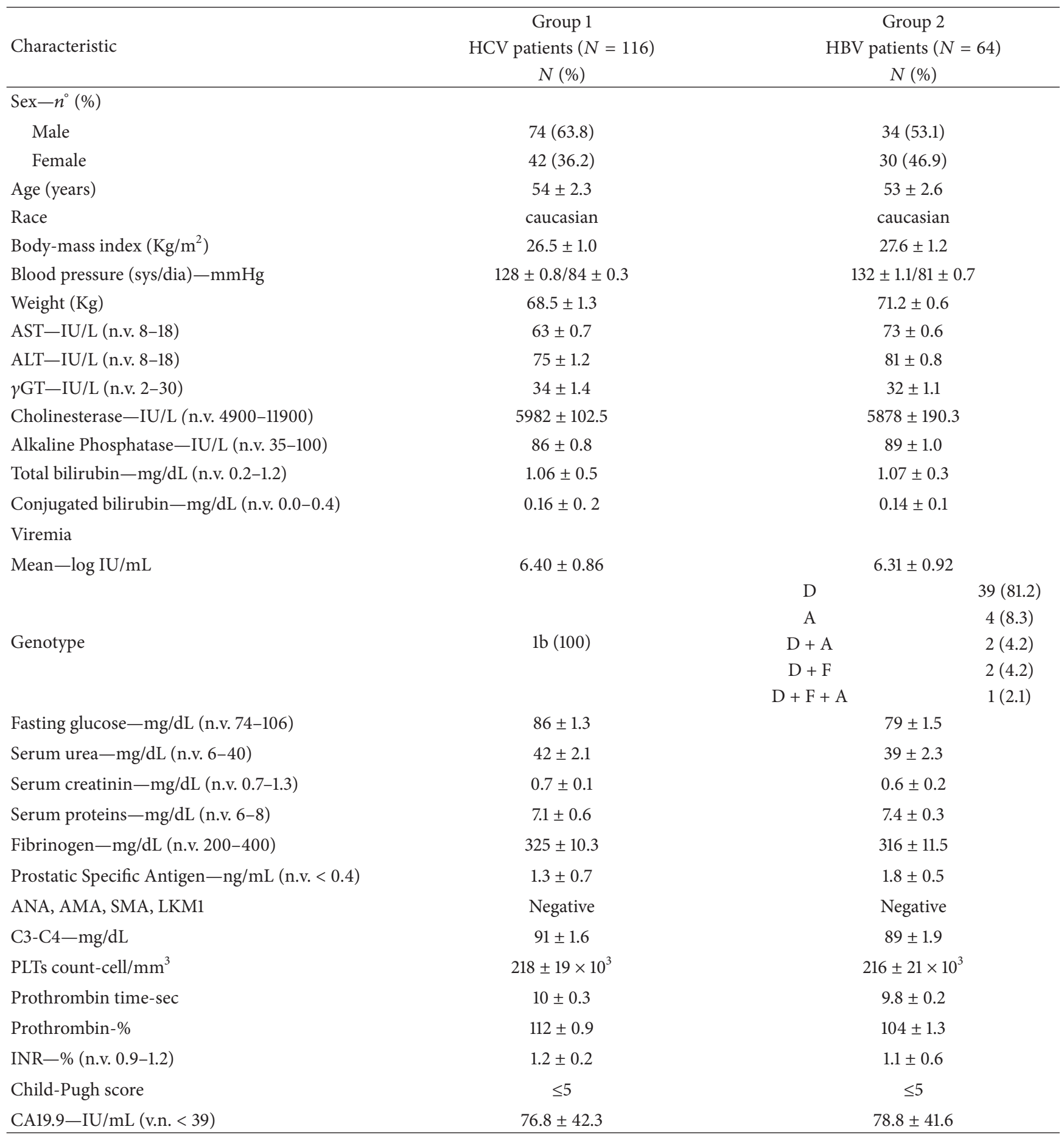

Values are expressed as the mean \pm SD. The body-mass index is the weight in kilograms divided by the square of the height in meters.

* Viremia stands for quantitative HCV-RNA in Group 1 and HBV-DNA in Group 2 respectively.

\section{Statistical Analysis}

Continuous variables have been presented with mean values \pm standard deviation (SD). Dichotomic variations will be expressed as frequencies, and significance was examined by a nonparametric statistical method (Mann-Whitney $U$ Test). $P<0.05$ was considered statistically significant.

\section{Results}

In group 1 (HCV infected subjects), none of patients (0/116; $0 \%)$ was found to have METAVIR score F0; 56/116 (48.3\%) patients resulted affected by chronic hepatitis (CH, METAVIR F1-F3) and 60/116 (51.7\%) by hepatic cirrhosis HCV-correlated (METAVIR F4). 60/116 (51.7\%) 
TABLE 2: Distribution of patients with elevated serum Ca19.9 according to METAVIR score.

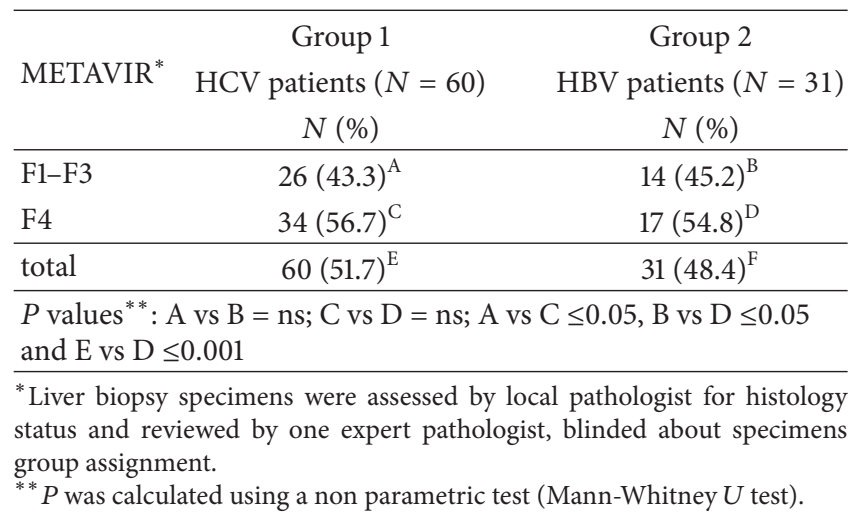

patients presented high serum levels of CA19.9 (mean value $76.8 \mathrm{UI} / \mathrm{mL}, \mathrm{SD}=42.3 \mathrm{UI} / \mathrm{mL}) ; 26 / 60$ (43.3\%) patients with score from F1 to F3; 34/60 (56.7\%) with score F4 (cirrhosis). In group 2 (HBV infected subject), all patients were $\mathrm{HBeAg}$ negative, anti-HBe positive, and anti-Delta negative; HBVDNA was detectable in $48 / 64(75 \%)$ patients. D genotype was found in $39 / 48(81.2 \%)$ cases, genotype $\mathrm{A}$ in $4 / 48(8.3 \%)$, genotype $\mathrm{D}+\mathrm{A}$ in $2 / 48$ (4.2\%), genotype $\mathrm{D}+\mathrm{F}$ in $2 / 48(4.2 \%)$, genotype $\mathrm{D}+\mathrm{F}+\mathrm{A}$ in $1 / 48(2.1 \%) .33 / 64$ (51.7\%) patients showed METAVIR F0; 14/64 (21.9\%) showed METAVIR F1F3 (CH); 17/64 (26.6\%) showed METAVIR F4 (cirrhosis). In this group, all patients with score $\geq$ F1 (31/64; 48.4\%), showed high serum levels of CA19.9 (mean value $78.8 \mathrm{UI} / \mathrm{mL}$, $\mathrm{SD}=41.6 \mathrm{UI} / \mathrm{mL}$ ). No patients were found with F0 score in group 1 as well as no increase of CA19.9 serum level was observed in patients with METAVIR score F0 in group 2 $(33 / 64 ; 51.7 \%)$. Our results showed that the increase of CA19.9 serum levels in patients with hepatic cirrhosis is statistically significant $(P<0.05)$ in comparison to CA19.9 increase in patients with chronic hepatitis, in both groups 1 and 2 (Tables 1 and 2). Furthermore, our results show a highly significant difference $(P<0.001)$ about the increase of CA19.9 serum levels considering the viral aetiology ( $\mathrm{HCV}$ versus $\mathrm{HBV}$ ) of the liver damage when a comparison is made between the overall amount of patients with elevated CA19.9 serum levels in both groups.

\section{Discussion}

Our data have shown that high levels of CA19.9 are a frequent event in viral chronic hepatitis HCV- and HBVrelated diseases, $51.7 \%$ and $48.4 \%$, respectively. They often cannot be considered as a sign of neoplastic disease and are statistically correlated with the severity of the disease $(P<$ 0.05 ) and with an increase of the fibrotic process. In fact, elevations of CA19.9 serum levels can be secondary to the necroinflammatory processes, to small bile ducts alterations, to the presence of regeneration nodules, and to the hyper production of raw collagen, which all are typical expression signs of chronic hepatitis progression to liver cirrhosis.
A number of studies have investigated the clinical utility of CA19.9 in diagnosing pancreatic cancer, cholangiocarcinoma, and other malignancies [20, 21]. Previous studies have shown that serum CA19.9 levels are also elevated in a broad range of benign and malignant conditions, including inflammatory bowel disease, rheumatoid arthritis, pancreatitis, achalasia, heavy tea consumption, Sjogren's syndrome, Hashimoto's thyroiditis, cholangiocarcinoma, colorectal, hepatocellular, esophageal, and lung and ovarian carcinomas [21-23].

CA19.9 is a mucinic type glycoprotein that is present only in traces in serum and is normally absent in other tissues such as pulmonary epithelium, perialveolar interstitial space, and liver. It is reasonable that any noxa (viral or toxic) which is able to promote tissue inflammatory damage and, sequentially, reparative features with fibrotic tissue deposition and parenchymal regeneration (as it happens in chronic liver disease, with intra- and interacinar fibrosis, nodular regeneration, and biliary neoductulation) can induce CA19.9 synthesis [24]. CA19.9 immunoreactivity was observed in cell membranes facing biliary canaliculi and in biliary ductules of hepatic bioptic specimens of patients with chronic hepatitis and liver cirrhosis [8]. Immunohistochemical analysis for CA19.9 showed high reactivity in hepatic inflammatory areas, in particular, in bile ductule cells and hepatocytes in ductular metaplasia, suggesting that these cells can be involved in CA19.9 synthesis, and its serum levels increase [8, 25-27].

The first outcome of our study is that it is necessary to carefully evaluate the use of CA19.9 as a tumoral marker in the presence of a chronic liver disease, because a high percentage of false positives can occur. Our data also focused on the possibility to use CA19.9 as indirect marker of hepatic fibrosis.

Some works in the literature report a statistically significant correlation between CA19.9 serum levels and some standard parameters of hepatic function: a positive correlation can be shown with levels of AST, ALT, alkaline phosphatase and bilirubin [17]. Other studies showed a correlation between CA19.9 (alone or together with CA 125) and the grade of hepatic fibrosis. In these studies two groups of patients have been examined, one with a F3-F4 METAVIR score (portal fibrosis without septa, or septal without cirrhosis) and one with a F4 METAVIR score (severe septal fibrosis with cirrhosis). CA19.9 serum levels (alone or together with other serum markers) can be used to individuate patients with severe fibrosis and cirrhosis [28].

Transaminases have been the first indirect hepatic fibrosis markers. They have been eventually associated to each other in the aspartate aminotransferase/alanine aminotransferase ratio (AAR) index [28]. Wai and other authors have proposed a further evolution of AAR index, by combining AST to platelet count [aspartate aminotransferase platelet ratio index (APRI)] [29-33].

\section{Conclusion}

The increase of CA19.9 serum levels are frequent in chronic viral hepatitis. In our population of patients with viral chronic hepatitis and cirrhosis, CA19.9 serum levels elevation does 
not indicate a contemporary neoplastic disease, but correlates in a statistically significant way $(P<0.05)$ with the grade of liver fibrosis, appearing to be more evident in patients with higher fibrosis score, thus correlating with the severity of the liver disease. A previous study showed similar results but was conducted on subjects with HCV and did not evaluate subject with HBV [34-36]. A novelty in this study could be represented by the elevation of CA19.9 serum levels that seems to be related to the viral aetiology, showing a high statistical significance when $\mathrm{HCV}$-infected are compared to the HBV-infected patients $(P<0.001)$. This could be explained by a more fibrogenic property of $\mathrm{HCV}$ than $\mathrm{HBV}$, but more researches must be conducted to better assess the specific role of the virus for Ca19.9 neosynthesis, while a direct interaction between HCV proteins and hepatic stellate cells (HSCs) may contribute to $\mathrm{HCV}$-induced liver fibrosis. Further investigations may clarify if CA19.9 can assume the role of indirect marker of hepatic fibrosis and be not only as neoplastic biomarker.

We propose that CA19.9 could be used in the combinations with the other markers already in use, in order to increase the diagnostic accuracy of the available tests, rising both the positive (PPV) and the negative (NPV) predictive values.

\section{Conflict of Interests}

The authors declare that they have no competing interests. GM was supported by the International Ph.D. programme in Neuropharmacology, University of Catania.

\section{References}

[1] Y. Motoo, Y. Satomura, I. Mouri et al., "Serum levels of pancreatitis-associated protein in digestive diseases with special reference to gastrointestinal cancers," Digestive Diseases and Sciences, vol. 44, no. 6, pp. 1142-1147, 1999.

[2] M. F. Plemenos, C. Dimas, A. Kotsios, K. Gennatas, and A. Kondi-Pafiti, "Prognostic significance of the immunohistochemical localization and serological detection of CA19-9 tumor antigen in colon carcinoma," Journal of B.U.ON, vol. 9, no. 1, pp. 73-76, 2004.

[3] K. Markocka-Maczka, "Ca 19-9 antigen in differentiation of pancreatic inflammatory and neoplastic tumors," Wiadomosci Lekarskie, vol. 56, no. 11-12, pp. 537-540, 2003.

[4] M. Ducreux, V. Boige, and D. Malka, "CA 19-9 and pancreatic carcinoma, a revival?” Onkologie, vol. 30, no. 1-2, pp. 12-13, 2007.

[5] A. Nouts, P. Lévy, H. Voitot, and P. Bernades, "Diagnostic value of Ca 19-9 antigen in patients with chronic pancreatitis or pancreatic adenocarcinoma: effects of complications," Gastroentérologie Clinique et Biologique, vol. 22, no. 2, pp. 152-159, 1998.

[6] N. Tanaka, S. Okada, H. Ueno, T. Okusaka, and M. Ikeda, "The usefulness of serial changes in serum CA19-9 levels in the diagnosis of pancreatic cancer," Pancreas, vol. 20, no. 4, pp. 378381,2000 .

[7] J. Nowak, D. Jakubowska, A. Wiczkowski et al., "Carbohydrate antigens CA 19-9, CA 242, CA 50 in liver diseases," Wiadomości Lekarskie, vol. 51, no. 11-12, pp. 484-491, 1998.
[8] Y. Kitagawa, M. Iwai, A. Muramatsu et al., "Immunohistochemical localization of CEA, CA19-9 and DU-PAN-2 in hepatitis C virus-infected liver tissues," Histopathology, vol. 40, no. 5, pp. 472-479, 2002.

[9] O. Uygur-Bayramiçli, R. Debak, E. Orbay et al., "Type 2 diabetes mellitus and CA 19-9 levels," World Journal of Gastroenterology, vol. 13, no. 40, pp. 5357-5359, 2007.

[10] É. Szekanecz, Z. Śandor, P. Antal-Szalmás et al., "Increased production of the soluble tumor-associated antigens CA19-9, CA125, and CA15-3 in rheumatoid arthritis: potential adhesion molecules in synovial inflammation?" Annals of the New York Academy of Sciences, vol. 1108, pp. 359-371, 2007.

[11] R. Safadi, M. Ligumsky, E. Goldin, Y. Ilan, Y. S. Haviv, and S. Nusair, "Increased serum CA 19-9 antibodies in Sjogren's syndrome," Postgraduate Medical Journal, vol. 74, no. 875, pp. 543-544, 1998.

[12] E. Giannini, P. Borro, F. Botta et al., "Cholestasis is the main determinant of abnormal CA 19-9 levels in patients with liver cirrhosis," International Journal of Biological Markers, vol. 15, no. 3, pp. 226-230, 2000.

[13] K. H. Park, J. S. Kim, J. H. Lee et al., "Significances of serum level and immunohistochemical stain of CA19-9 in simple hepatic cysts and intrahepatic biliary cystic neoplasms," The Korean Journal of Gastroenterology, vol. 47, no. 1, pp. 52-58, 2006.

[14] X. Vandemergel, F. Vandergheynst, and G. Decaux, "Very high elevation of CA19-9 level in a patient with steatosis," Acta Gastro-Enterologica Belgica, vol. 68, no. 3, pp. 380-381, 2005.

[15] M. Montalto, L. Santoro, M. Vastola et al., "Normalisation of high CA 19-9 values in autoimmune hepatitis after steroidal treatment," International Journal of Immunopathology and Pharmacology, vol. 18, no. 3, pp. 603-607, 2005.

[16] E. De Goede and S. H. Yap, "An exceptional high concentration of serum CA 19.9 in a patient with alcoholic liver disease," Gut, vol. 41, no. 4, pp. 579-580, 1997.

[17] S. Maestranzi, R. Przemioslo, H. Mitchell, and R. A. Sherwood, "The effect of benign and malignant liver disease on the tumour markers CA19-9 and CEA," Annals of Clinical Biochemistry, vol. 35, no. 1, pp. 99-103, 1998.

[18] P. Simmonds, A. Alberti, H. J. Alter et al., "A proposed system for the nomenclature of hepatitis C viral genotypes," Hepatology, vol. 19, no. 5, pp. 1321-1324, 1994.

[19] P. Bedossa and T. Poynard, "An algorithm for the grading of activity in chronic hepatitis C. The METAVIR Cooperative Study Group," Hepatology, vol. 24, no. 2, pp. 289-293, 1996.

[20] T. Kodama, H. Satoh, H. Ishikawa, and M. Ohtsuka, "Serum levels of CA19-9 in patients with nonmalignant respiratory diseases," Journal of Clinical Laboratory Analysis, vol. 21, no. 2, pp. 103-106, 2007.

[21] W. Steinberg, "The clinical utility of the CA 19-9 tumorassociated antigen," American Journal of Gastroenterology, vol. 85, no. 4, pp. 350-355, 1990.

[22] A. Andriulli, T. Gindro, P. Piantino et al., "Prospective evaluation of the diagnostic efficacy of CA 19-9 assay as a marker for gastrointestinal cancers," Digestion, vol. 33, no. 1, pp. 26-33, 1986.

[23] G. Bertino, A. Ardiri, M. Malaguarnera, G. Malaguarnera, N. Bertino, and G. S. Calvagno, "Hepatocellualar carcinoma serum markers," Seminars in Oncology, vol. 39, pp. 410-433, 2012.

[24] M. Schöniger-Hekele and C. Müller, "The combined elevation of tumor markers CA 19-9 and CA 125 in liver disease patients is highly specific for severe liver fibrosis," Digestive Diseases and Sciences, vol. 51, no. 2, pp. 338-345, 2006. 
[25] G. Malaguarnera, I. Paladina, M. Giordano, M. Malaguarnera, G. Bertino, and M. Berretta, "Serum markers of intrahepatic cholangiocarcinoma," Disease Markers, vol. 34, pp. 219-228, 2013.

[26] G. Malaguarnera, M. Giordano, I. Paladina et al., "Markers of bile duct tumors," World Journal of Gastrointestinal Oncology, vol. 3, pp. 49-59, 2011.

[27] G. Malaguarnera, M. Giordano, I. Paladina, M. Berretta, A. Cappellani, and M. Malaguarnera, "Serum markers of hepatocellular carcinoma," Digestive Diseases and Sciences, vol. 55, no. 10, pp. 2744-2755, 2010.

[28] E. Giannini, D. Risso, F. Botta et al., "Validity and clinical utility of the aspartate aminotransferase-alanine aminotransferase ratio in assessing disease severity and prognosis in patients with hepatitis C virus-related chronic liver disease," Archives of Internal Medicine, vol. 163, no. 2, pp. 218-224, 2003.

[29] C.-T. Wai, J. K. Greenson, R. J. Fontana et al., "A simple noninvasive index can predict both significant fibrosis and cirrhosis in patients with chronic hepatitis C," Hepatology, vol. 38, no. 2, pp. 518-526, 2003.

[30] N. V. Chrysanthos, G. V. Papatheodoridis, S. Savvas et al., "Aspartate aminotransferase to platelet ratio index for fibrosis evaluation in chronic viral hepatitis," European Journal of Gastroenterology and Hepatology, vol. 18, no. 4, pp. 389-396, 2006.

[31] F. Imbert-Bismut, V. Ratziu, L. Pieroni, F. Charlotte, Y. Benhamou, and T. Poynard, "Biochemical markers of liver fibrosis in patients with hepatitis C virus infection: a prospective study," The Lancet, vol. 357, no. 9262, pp. 1069-1075, 2001.

[32] K. A. Gebo, H. F. Herlong, M. S. Torbenson et al., "Role of liver biopsy in management of chronic hepatitis C: a systematic review," Hepatology, vol. 36, no. 5 I, pp. S161-S172, 2002.

[33] R. Bataller, Y.-H. Paik, J. N. Lindquist, J. J. Lemasters, and D. A. Brenner, "Hepatitis $\mathrm{C}$ virus core and nonstructural proteins induce fibrogenic effects in hepatic stellate cells," Gastroenterology, vol. 126, no. 2, pp. 529-540, 2004.

[34] G. Bertino, A. M. Ardiri, P. Boemi et al., "Meaning of elevated CA 19-9 serum levels in chronic hepatitis and HCV-related cirrhosis," Minerva Gastroenterologica e Dietologica, vol. 53, no. 4, pp. 305-309, 2007.

[35] T. Stroffolini, A. Spadaro, V. Di Marco et al., "Current practice of chronic hepatitis B treatment in Southern Italy," European Journal of Internal Medicine, vol. 23, pp. 124-127, 2012.

[36] G. Bertino, A. Ardiri, P. M. Boemi et al., "Epoetin alpha improves the response to antiviral treatment in HCV-related chronic hepatitis," European Journal of Clinical Pharmacology, vol. 66, pp. 1055-1063, 2010. 


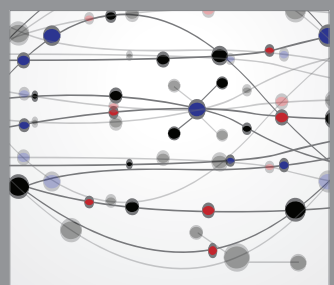

The Scientific World Journal
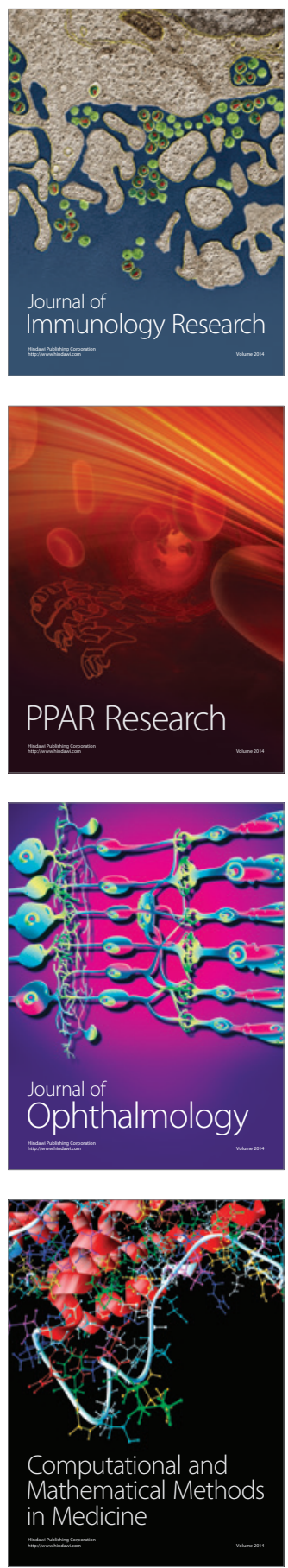

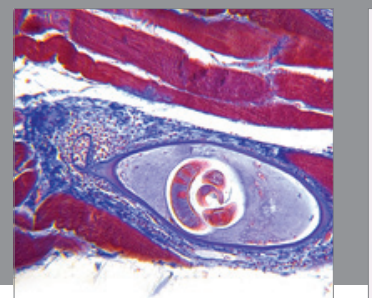

Gastroenterology

Research and Practice
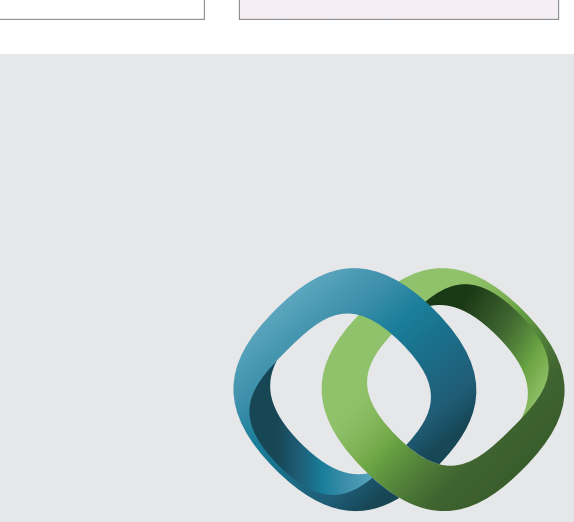

\section{Hindawi}

Submit your manuscripts at

http://www.hindawi.com
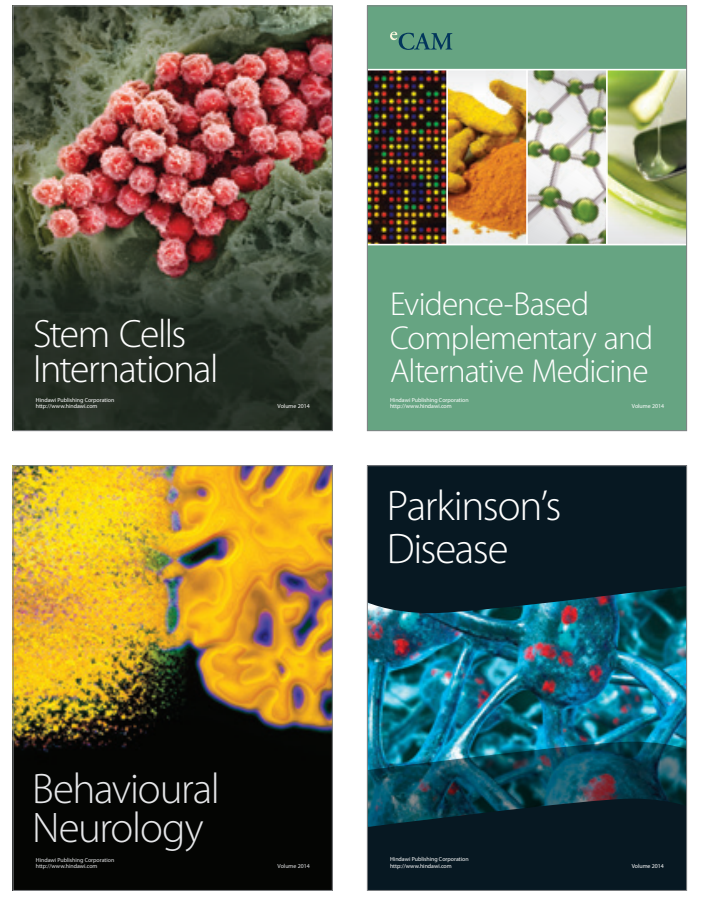
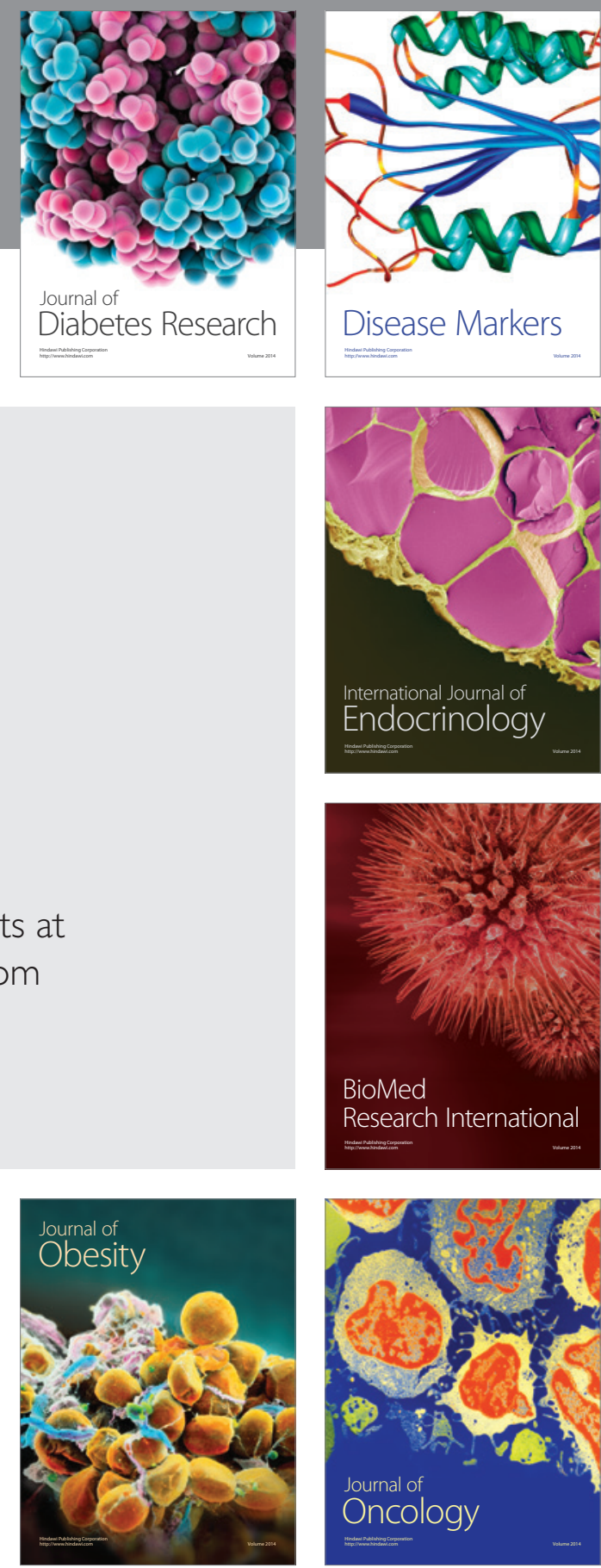

Disease Markers
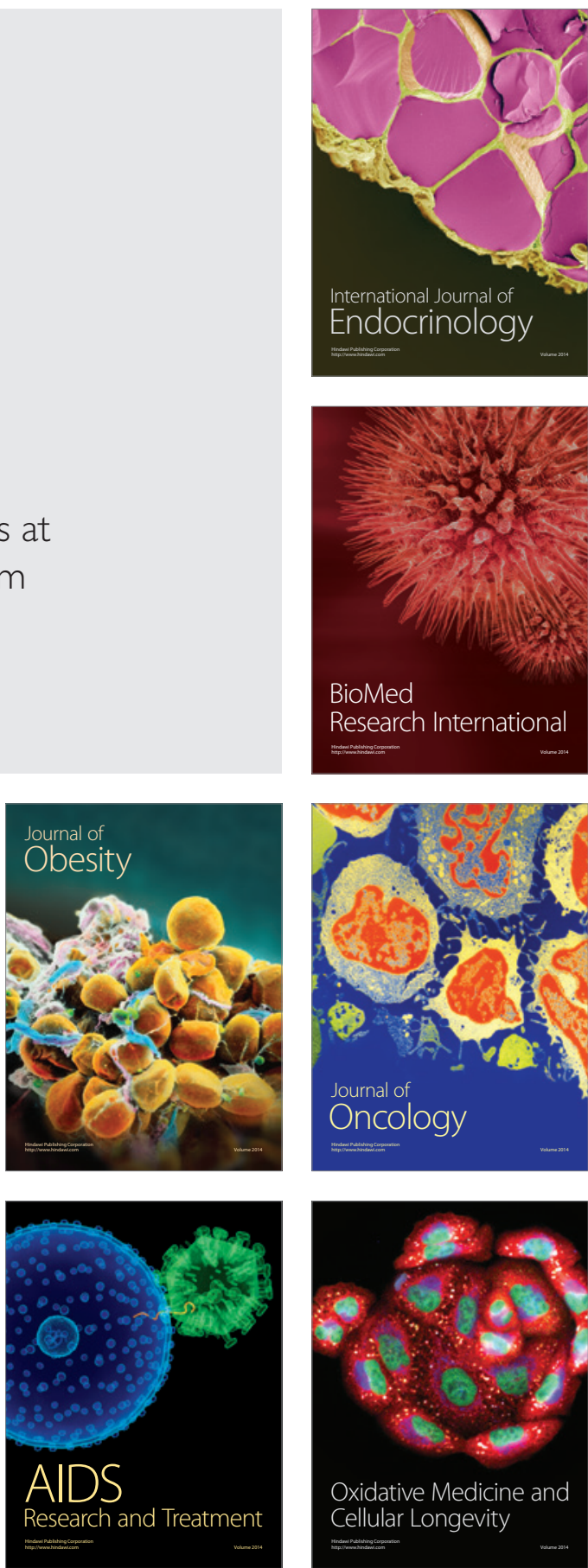